\title{
Themed issue on advances in solid state chemistry and its applications
}

\author{
Caroline A Kirk ${ }^{\mathrm{a}}$, Finlay D Morrison ${ }^{\mathrm{b}}$, Jan Skakle ${ }^{\mathrm{c}}$, Derek C Sinclair ${ }^{\mathrm{d}}$ and John T S Irvine ${ }^{\mathrm{b}}$
}

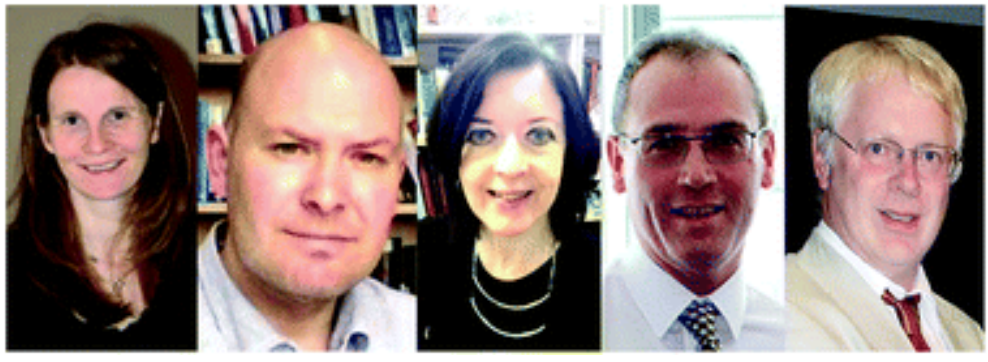

A themed issue on advances in solid state chemistry and its applications, in celebration of Professor Tony West's 70th birthday.

a University of Edinburgh, School of Chemistry, Edinburgh, UK

$b$ University of St Andrews, School of Chemistry, St Andrews, Fife, KY16 9ST, UK

c University of Aberdeen, Department of Chemistry, Aberdeen, AB24 3UE, UK

$d$ University of Sheffield, Sheffield, S1 3JD, UK

Tony West has not only defined the field of solid state chemistry through his writings, he has also pioneered the domain of materials chemistry that is so important in our new "materials world". He has an outstanding international reputation as an educator, researcher and ambassador. His wide-ranging research has evolved from the domains of silicate chemistry through solid state electrochemistry, via ionic and electronic conductors to electric materials. He has specialised in the synthesis of new oxide materials, crystal structure determination and structure-property relations. Two of his trademark approaches are the construction and application of equilibrium phase diagrams to investigate phase relations in complex oxide systems, and the development of impedance spectroscopy for materials and microstructural characterisation and electrical property measurements. As well as his activities in solid state chemistry, he has had a defining impact in the emerging field of materials chemistry. He was the driving force in establishing the Journal of Materials Chemistry, serving as Scientific Editor for the first year and Chair of the Editorial Board for the first ten years. During this period he also established the International Conference Series on Materials Chemistry $\left(M C^{n}\right)$, and chaired $\mathrm{MC}^{1}$ in Aberdeen in 1995. He has, therefore, had a major role in establishing materials chemistry as a recognised branch of chemistry, also establishing the Materials Chemistry Forum of the Royal Society of Chemistry (RSC), which is now a fully recognised Division of the RSC. Throughout his career he has received several awards in solid state chemistry, materials science and materials chemistry; the most recent is the
RSC's 2013 John B. Goodenough Lifetime Award, "for his outstanding contribution to our understanding of structurecomposition-property relationships in oxide-based materials, and their application in solid state devices, and for his preeminent role in promoting materials chemistry". He has been appointed a member of many UK and international committees in the scientific field, including President of the Inorganic Division, International Union of Pure and Applied Chemistry (IUPAC), 2004-2007. On the occasion of his 70th birthday, we honour his significant contributions to the fields of solid state and materials chemistry in this collection of papers that have been authored by many of his friends, colleagues, co-workers and former students. The topics covered suitably reflect the diversity of Tony's interests in the synthesis and characterisation of exciting new and/or important materials for energy and sustainability, and J. Mater. Chem. A is a fitting home for their publication. Tony's influence has reached across the globe and this is reflected in the international authorship in this collection, with particularly strong representation from Spain and Mexico, where he has spent significant periods of his career training new researchers and developing collaborative links. Tony spent much of his early career at the University of Aberdeen, Department of Chemistry (where he obtained his PhD under the guidance of Fred Glasser), where his interest in solid state chemistry was nurtured by a quite remarkable faculty presence in this area (including Taylor, both Glassers, Duffy and Ingram). He rose through these ranks to become Professor of Chemistry in 1989 before moving to the University of Sheffield, Department of Materials Science and Engineering, as Head of Department in 1999, a post he held until 2007. Tony is Professor of Electroceramics and Solid State Chemistry at Sheffield, and has authored or co-authored over 500 publications, including the seminal book Solid State Chemistry and its Applications. ${ }^{1}$ The first edition (1985) was based on over 150 lectures given in Mexico (UNAM, Mexico City) in the early 1980s; a second edition appeared in 2014 following many scientific advances in inorganic materials throughout the late ' 80 s and '90s. Together with his abridged editions, Basic Solid State Chemistry, ${ }^{2}$ published in 1988 and 1999, Tony's texts are still considered "the textbooks" for solid state chemistry, with sales in excess of 12000 copies and translations into several languages, including Japanese, Chinese and Arabic. In addition to Tony's prolific scientific and book-writing output, he has an outstanding record in mentoring and developing young researchers, having supervised more than 50 students to PhD success as well as an excellent cadre of postdoctoral researchers, many of whom have contributed to this volume. We hope that you enjoy reading the scientific output in this collection.

\section{References}

1. A. R.West, Solid State Chemistry and its Applications, John Wiley \& Sons, 2nd edn., 2014.

2. A. R. West, Basic Solid State Chemistry, John Wiley \& Sons, 2nd edn., 1999. 